\title{
PREVALENCE OF KERATOCONUS IN EGYPTIAN ASTIGMATIC PATIENTS
}

\author{
By
}

\section{Mohammed El-Sayed Fawzy Abd El-Hafez, Ahmed Salah Abd El-Rehim and Nour El-Din Abd El-Hamid Abd El-Halim}

Department of Ophthalmology, Faculty of Medicine, Al-Azhar University, Cairo, Egypt

Corresponding Author: Mohammed El-Sayed Fawzy Abd El-Hafez,

E-mail: mohammed-fawzy20@ @otmail.com

\begin{abstract}
Background: Keratoconus is a corneal ectatic disease characterized by progressive, non-inflammatory corneal disorder, which is characterized by thinning, protrusion of central or paracentral portion of the cornea resulting in irregular astigmatism, myopia, corneal scarring and reduction in visual acuity. The onset of the keratoconus usually occurs at puberty with the progression until the third to fourth decade of the life in most of the cases.
\end{abstract}

Objective: To estimate the prevalence of keratoconus in Egyptian people who have corneal astigmatism using pentacam as an imaging device.

Patients and Methods: A retrospective study was done at Al-Sayed Galal University Hospital in Ophthalmology outpatient clinics. The retrieved data revealed 80 eyes of 40 patients photographed during the period from June 2019 to December 2019 by using Scheimpflug imaging device (pentacam) as screening device for keratoconus. All such cases underwent a complete ophthalmic examination that includes visual acuity measurement, refraction, slit lamp biomicroscopy, retinoscopy, fundus examination and corneal topography (pentacam).

Results: Mean age of our study cases was $26.55 \pm 8$ years, which included $22(55 \%)$ males and $18(45 \%)$ females. Cases with $\mathrm{KC}$ have higher keratometric corneal values (k1, k2, kmax) and thinner pachymetric values than normal astigmatic eyes.

Conclusion: The higher the astigmatism was the higher risk to have keratoconus. Cases with astigmatism $\geq$ $1.5 \mathrm{D}$ who present to outpatient clinics, should undergo corneal topography screening for early diagnosis of $\mathrm{KC}$ even if visual acuity is not affected. Pentacam may provide more accurate information about anterior and posterior corneal anatomy especially in suspected eyes.

Keywords: Keratoconus, Astigmatism, Pentacam.

\section{INTRODUCTION}

Astigmatism is a commonly encountered refractive error, accounting for about 13 percent of the refractive errors of the human eye. Keratoconus is bilateral but (usually asymmetrical) corneal disease, characterized by paraxial stromal thinning and weakening that leads to corneal surface distortion. The reported prevalence of keratoconus varies widely depending on geographic location, diagnostic criteria used, and the cohort of the patients selected (Hashemi et al., 2018). Visual disturbance occurs primarily from irregular astigmatism and myopia, and secondary from corneal scarring (Toprak et al., 2015). 
Pentacam used to diagnose and detect the progression in patients with keratoconus and also provide detailed information about corneal tomography and topography (Piñero et al., 2010).

In the last few years, it has been shown that in healthy individuals, the posterior corneal surface has not only a different amount of astigmatism but also a different alignment of the steep meridian (Piñero et al., 2012 and Sugar \& Macsai, 2012).

Assessment of corneal astigmatism at both surfaces play an important role in vision correction procedures, e.g. rigid gas permeable contact lens fit and implantation of a toric intraocular lens (IOL). Studies reported that ignoring posterior corneal astigmatism may significantly affect the estimation of corneal astigmatism. Since manifestations of keratoconus occur at the posterior corneal surface even in early stages of the disease, identifying these changes could help clinicians to detect early stages of keratoconus (De Sanctis et al., 2011 and Fares et al., 2012).

The aim of this study was to determine the prevalence of keratoconus in subjects with astigmatism $(-1.5 \mathrm{D})$ or greater using data from the pentacam scheimpflug tomography.

\section{PATIENTS AND METHODS}

A retrospective study was done at AlSayed Galal University Hospital in Ophthalmology outpatient clinics. The retrieved data revealed 80 eyes of 40 patients photographed during the period from June 2019 to December 2019 by using Scheimpflug imaging device (pentacam) as screening device for keratoconus.
The study was conducted on patients of middle age group from 18 years old to 40 years old of both sex with keratometric myopic astigmatism $\geq 1.5 \mathrm{D}$ were only included in this study. The number of the selected cases was 80 eyes of 40 patients with myopic astigmatism $\geq 1.5 \mathrm{D}$ bilaterally. Full history was taken including age, past medical history, past ophthalmic history, and if they were complaining of any symptoms other than errors of refraction.

The patients were classified into 2 groups: Group A (26 patients, 52 eyes) with myopic astigmatism from $-1.5 \mathrm{D}$ to 3.0D and Group B (14 patients, 28 eyes) with myopic astigmatism more than-3.0D.

\section{Ethical approval and written informed consent:}

An approval of the study was obtained from Al- Azhar University academic and ethical committee. Every patient signed an informed written consent for acceptance of the operation.

\section{Exclusion criteria:}

- Corneal opacities.

- Patients with uveitis.

- Glucomatous patients.

- History of intraocular foreign body.

- Best corrected visual acuity less than 6160.

- Patients with retinal detachment.

All the selected cases were diagnosed as astigmatism $\geq 1.5 \mathrm{D}$ from outpatient clinics were investigated by pentacam.

\section{Statistical analysis:}

Data collected throughout history, basic clinical examination, laboratory 
investigations and outcome measures coded, entered and analyzed using Microsoft Excel software. The data collected were tabulated and analyzed by SPSS (Statistical Package for Social Science) version 25 (Armonk, NY: IBM Corp) on IBM compatible computer. The qualitative data were presented as numbers and percentages and compared between groups using Chi-square test. Also, quantitative data with parametric distribution were presented as means, standard deviations and compared between the two groups using Independent t-test while quantitative data with non-parametric distribution were presented as median, inter-quartile range (IQR) and range and compared between the two groups using Mann-Whitney test. The confidence interval was set to $95 \%$ and the margin of error accepted was set to $5 \%$, so the p-value was considered significant at $\mathrm{p}<0.05$.

\section{RESULTS}

Pentacam of a patient in group (A) showing refractive maps of positive keratoconus in the right eye (Figure 1).

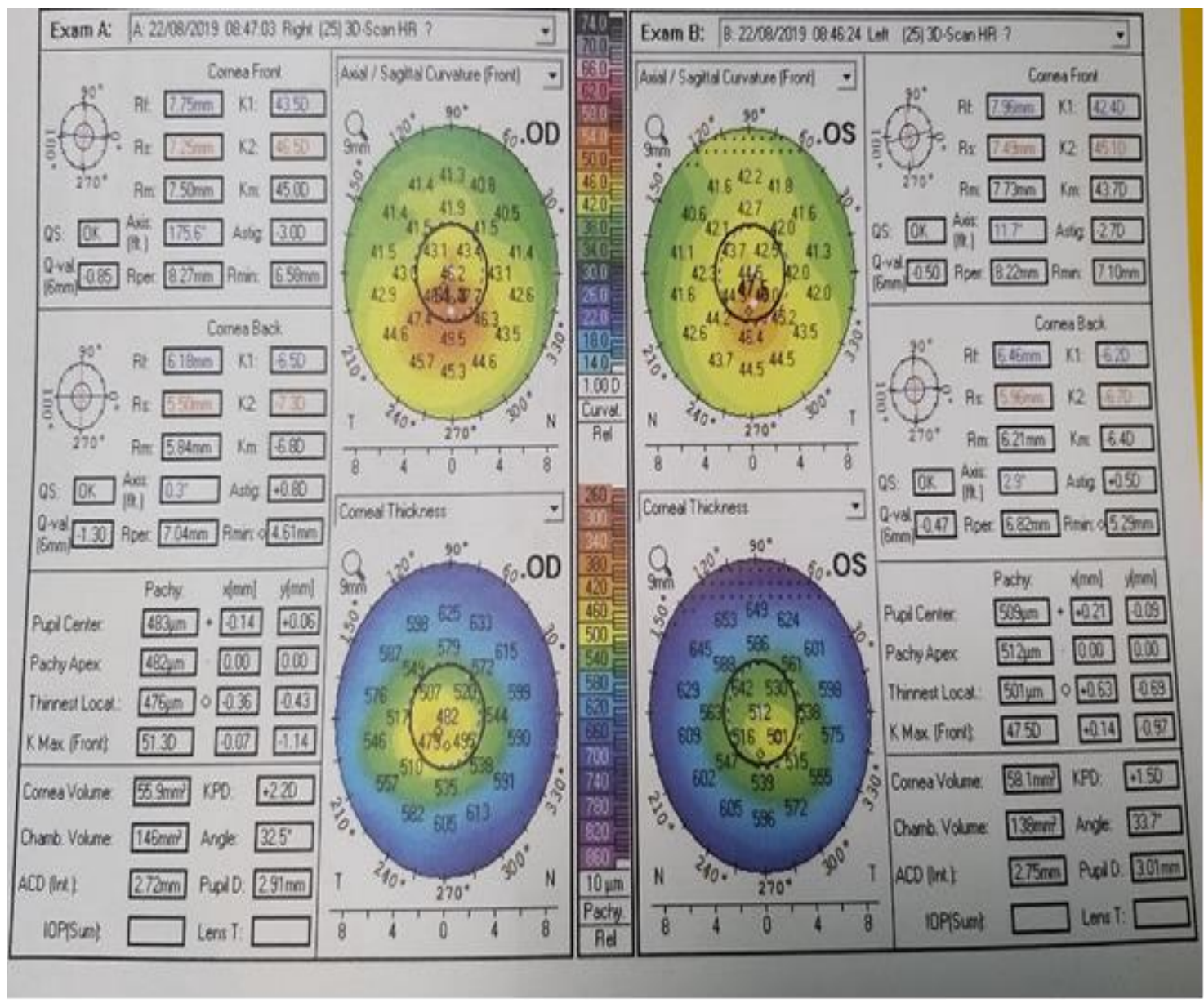

Figure (1): Pentacam of patient in $\operatorname{group}(\mathbf{A})$. 
Pentacam of a patient in group (B) showing Belin/Ambrósio display of positive keratoconus in the left eye (Figure 2).

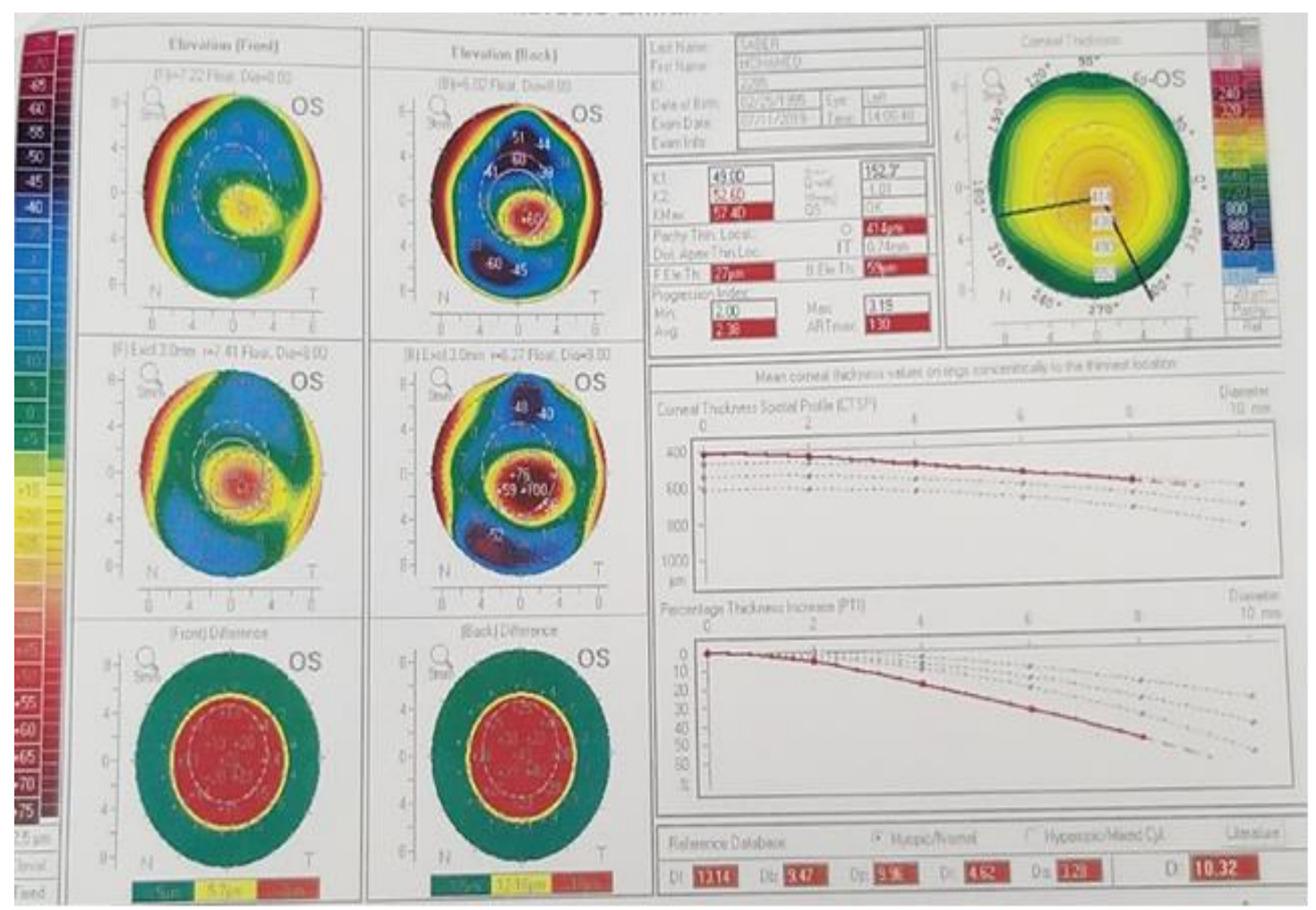

Figure (2): Belin/Ambrósio display of patient in group (B)

There was no statistically significant difference found between two groups regarding age and gender (Table 1).

Table (1): Comparison between (Group A \& Group B) regarding age and gender of Patients

\begin{tabular}{|c|c|c|c|c|}
\hline \multirow{2}{*}{ Parameters } & Groups & Group A & Group B & \multirow{2}{*}{ P-value } \\
\cline { 2 - 4 } Age & Mean \pm SD & No. $=\mathbf{2 6}$ & No. $=\mathbf{1 4}$ & \\
\cline { 2 - 4 } & Range & $18.62 \pm 5.25$ & $25.14 \pm 4.59$ & \multirow{2}{*}{0.779} \\
\hline \multirow{2}{*}{ Sex } & Female & $12(46.2 \%)$ & $6(42.9 \%)$ & \multirow{2}{*}{0.842} \\
\cline { 2 - 4 } & Male & $14(53.8 \%)$ & $8(57.1 \%)$ & \\
\hline
\end{tabular}

Independent t-test, Chi-square test

A comparison between group (A) and group (B) is applied as regard all parameters was done and there was highly statistically significant difference. According K readings; K1 was 43.32D in group A vs $46.93 \mathrm{D}$ in group B, K2 was 45.44D vs $51.63 \mathrm{D}$, astigmatism was
$2.25 \mathrm{D}$ vs $4 \mathrm{D}$, pachy Apex was $518 \mu \mathrm{m}$ vs $482.64 \mu \mathrm{m}$, thinnest location was 514.21 $\mu \mathrm{m}$ vs $459.43 \mu \mathrm{m}$ and kmax was $45.55 \mathrm{D}$ vs $52.05 \mathrm{D}$. (K1, flat keratometry; K2, steep keratometry; Kmax, maximum simulated keratometry) (Table 2). 
Table (2): Comparison between the different parameters in group (A) and group (B).

\begin{tabular}{|c|c|c|c|c|}
\hline \multirow{2}{*}{\multicolumn{2}{|c|}{\begin{tabular}{|ll} 
Parameters & Groups \\
\end{tabular}}} & Group A & Group B & \multirow{2}{*}{$\begin{array}{c}P- \\
\text { value }\end{array}$} \\
\hline & & No. $=52$ & No. $=28$ & \\
\hline \multirow{2}{*}{ Astigmatism(D) } & Median (IQR) & $2.25(1.75-2.5)$ & $4(3.63-5.13)$ & \multirow{2}{*}{$<0.001$} \\
\hline & Range & $1.5-3$ & $3.25-8$ & \\
\hline \multirow{2}{*}{ K1 (D) } & Mean \pm SD & $43.23 \pm 2.73$ & $46.93 \pm 6.95$ & \multirow{2}{*}{0.001} \\
\hline & Range & $38.7-55.4$ & $38.9-71.3$ & \\
\hline \multirow{2}{*}{ K2 (D) } & Mean \pm SD & $45.44 \pm 2.85$ & $51.63 \pm 7.21$ & \multirow{2}{*}{$<0.001$} \\
\hline & Range & $40.2-57.9$ & $44-75.1$ & \\
\hline \multirow{2}{*}{ Pachy Apex $(\mu \mathrm{m})$} & Mean \pm SD & $518.00 \pm 46.97$ & $482.64 \pm 55.70$ & \multirow{2}{*}{$<0.001$} \\
\hline & Range & $410-604$ & $372-587$ & \\
\hline \multirow{2}{*}{ Thinnest Location $(\mu \mathrm{m})$} & Mean \pm SD & $514.21 \pm 47.56$ & $459.43 \pm 69.93$ & \multirow{2}{*}{$<0.001$} \\
\hline & Range & $405-602$ & $310-582$ & \\
\hline \multirow{2}{*}{$\mathrm{Kmax}(\mathrm{D})$} & Median (IQR) & $45.55(44.2-47.0)$ & $52.05(47.60-61.75)$ & \multirow{2}{*}{$<0.001$} \\
\hline & Range & $43.1-60.5$ & $45.4-91.6$ & \\
\hline
\end{tabular}

Mann-Whitney test, Independent t-test

A comparison between positive and negative keratoconus in group $\mathrm{A}$ is applied as regard all parameters was done and there was highly statistically significant difference. According $\mathrm{K}$ readings; $\mathrm{K} 1$ was $46.22 \mathrm{D}$ in positive $\mathrm{KC}$ vs $42.34 \mathrm{D}$ in negative $\mathrm{KC}$, $\mathrm{K} 2$ was $48.58 \mathrm{D}$ vs $44.5 \mathrm{D}$, pachy Apex was 478 $\mu \mathrm{m}$ vs $530 \mu \mathrm{m}$, thinnest location was $472.5 \mu \mathrm{m}$ vs $526.73 \mu \mathrm{m}$ and kmax was $51.8 \mathrm{D}$ vs $45.15 \mathrm{D}$.
A comparison between positive and negative keratoconus in group B is applied as regard all parameters were done and there was highly statistically significant difference. According K readings; K1 was 50.03D in positive $\mathrm{KC}$ vs $42.8 \mathrm{D}$ in negative $\mathrm{KC}, \mathrm{K} 2$ was $55.08 \mathrm{D}$ vs $47.03 \mathrm{D}$, pachy Apex was $450.13 \mu \mathrm{m}$ vs $526 \mu \mathrm{m}$, thinnest location was $414.88 \mu \mathrm{m}$ vs $518.83 \mu \mathrm{m}$ and kmax was $59.6 \mathrm{D}$ vs $45.9 \mathrm{D}$ (Table 3). 
Table (3): Comparison between -ve and +ve keratoconus in group A and group B.

\begin{tabular}{|c|c|c|c|c|}
\hline \multirow{2}{*}{\multicolumn{2}{|c|}{ Group A }} & \multirow{2}{*}{$\begin{array}{c}\text { Negative KC } \\
\text { No. }=\mathbf{4 0} \\
\end{array}$} & \multirow{2}{*}{$\begin{array}{c}\text { Positive KC } \\
\text { No. }=12\end{array}$} & \multirow{2}{*}{$\begin{array}{c}\text { P- } \\
\text { value }\end{array}$} \\
\hline & & & & \\
\hline \multirow{2}{*}{ Astigmatism(D) } & Median (IQR) & $2.25(1.75-2.50)$ & $2.38(2.25-2.50)$ & \multirow{2}{*}{0.516} \\
\hline & Range & $1.5-3$ & $1.5-3$ & \\
\hline \multirow{2}{*}{ K1(D) } & Mean \pm SD & $42.34 \pm 0.80$ & $46.22 \pm 4.43$ & \multirow[t]{2}{*}{$<0.001$} \\
\hline & Range & $40.9-44.5$ & $38.7-55.4$ & \\
\hline \multirow{2}{*}{ K2 (D) } & Mean \pm SD & $44.50 \pm 0.87$ & $48.58 \pm 4.57$ & \multirow[t]{2}{*}{$<0.001$} \\
\hline & Range & $43-47$ & $40.2-57.9$ & \\
\hline \multirow{2}{*}{ Pachy Apex $(\mu \mathrm{m})$} & Mean \pm SD & $530.00 \pm 36.96$ & $478.00 \pm 55.84$ & \multirow[t]{2}{*}{$<0.001$} \\
\hline & Range & $454-604$ & $410-566$ & \\
\hline \multirow{2}{*}{$\begin{array}{l}\text { Thinnest Location } \\
(\mu \mathrm{m})\end{array}$} & Mean \pm SD & $526.73 \pm 36.99$ & $472.50 \pm 56.30$ & \multirow[t]{2}{*}{$<0.001$} \\
\hline & Range & $452-602$ & $405-559$ & \\
\hline \multirow{2}{*}{ K. Max (D) } & Median (IQR) & $45.15(44.2-45.85)$ & $51.80(47.7-55.1)$ & \multirow[t]{2}{*}{$<0.001$} \\
\hline & Range & $43.1-49.5$ & $46.4-60.5$ & \\
\hline \multirow{2}{*}{\multicolumn{2}{|c|}{ Group B }} & Negative KC & Positive KC & \multirow{2}{*}{$\begin{array}{c}\text { P- } \\
\text { value }\end{array}$} \\
\hline & & No. $=10$ & No. $=18$ & \\
\hline \multirow{2}{*}{ Astigmatism (D) } & Median (IQR) & $4.25(4-4.75)$ & $4(3.5-5.5)$ & \multirow{2}{*}{0.738} \\
\hline & Range & $3.25-5.25$ & $3.25-8$ & \\
\hline \multirow{2}{*}{$\mathrm{K} 1$ (D) } & Mean \pm SD & $42.80 \pm 2.60$ & $50.03 \pm 7.63$ & \multirow{2}{*}{0.008} \\
\hline & Range & $38.9-47$ & $43.4-71.3$ & \\
\hline \multirow{2}{*}{ K2 (D) } & Mean \pm SD & $47.03 \pm 2.20$ & $55.08 \pm 7.77$ & \multirow[t]{2}{*}{$<0.001$} \\
\hline & Range & $44-50.8$ & $47.3-75.1$ & \\
\hline \multirow{2}{*}{ Pachy Apex $(\mu \mathrm{m})$} & Mean \pm SD & $526.00 \pm 40.65$ & $450.13 \pm 41.73$ & \multirow[t]{2}{*}{$<0.001$} \\
\hline & Range & $472-587$ & $372-529$ & \\
\hline \multirow{2}{*}{ Thinnest Location $(\mu \mathrm{m})$} & Mean \pm SD & $518.83 \pm 39.60$ & $414.88 \pm 52.08$ & \multirow[t]{2}{*}{$<0.001$} \\
\hline & Range & $465-582$ & $310-486$ & \\
\hline \multirow{2}{*}{$\mathrm{Kmax}(\mathrm{D})$} & Median (IQR) & $45.9(45.7-48)$ & $59.6(52.1-65.0)$ & \multirow[t]{2}{*}{0.006} \\
\hline & Range & $45.4-52$ & $51.4-91.6$ & \\
\hline
\end{tabular}

Mann-Whitney test, Independent t-test

A comparison between right eyes in both groups is applied as regard all parameters was done and there was highly statistically significant difference except in pachy Apex. According K readings; K1 was $43.54 \mathrm{D}$ in group $\mathrm{A}$ vs $48 \mathrm{D}$ in group $\mathrm{B}, \mathrm{K} 2$ was $45.79 \mathrm{D}$ vs $52.6 \mathrm{D}$, astigmatism was $2.25 \mathrm{D}$ vs $4.13 \mathrm{D}$, pachy Apex was 516 $\mu \mathrm{m}$ vs $480.5 \mu \mathrm{m}$, thinnest location was $512.19 \mu \mathrm{m}$ vs $458.93 \mu \mathrm{m}$ and kmax was 45.7D vs 52.1D.
A comparison between left eyes in both groups is applied as regard all parameters was done and there was highly statistically significant difference. According K readings; K1 was 42.92D in group A vs $45.86 \mathrm{D}$ in group B, K2 was 45.09D vs $50.66 \mathrm{D}$, astigmatism was $2.5 \mathrm{D}$ vs $3.5 \mathrm{D}$, pachy Apex was $520 \mu \mathrm{m}$ vs $484.79 \mu \mathrm{m}$, thinnest location was $516.23 \mu \mathrm{m}$ vs $459.93 \mu \mathrm{m}$ and kmax was 45.3D vs 53.6D (Table 4). 
Table (4): Comparison between the different parameters in right and left eyes of both groups

\begin{tabular}{|c|c|c|c|c|}
\hline \multirow{2}{*}{\multicolumn{2}{|c|}{$\begin{array}{ll}\text { Parameters } & \text { Groups } \\
\end{array}$}} & Group A & Group B & \multirow{2}{*}{ P-value } \\
\hline & & No. $=26$ & No. $=14$ & \\
\hline \multicolumn{5}{|l|}{ Right: } \\
\hline \multirow{2}{*}{ Astigmatism(D) } & Median (IQR) & $2.25(1.75-2.50)$ & $4.13(3.75-5.0)$ & \multirow{2}{*}{$<0.001$} \\
\hline & Range & $1.5-3$ & $3.25-7$ & \\
\hline \multirow{2}{*}{ K1 (D) } & Mean \pm SD & $43.54 \pm 3.04$ & $48.00 \pm 9.25$ & \multirow{2}{*}{0.030} \\
\hline & Range & $41-55.4$ & $38.9-71.3$ & \\
\hline \multirow{2}{*}{ K2 (D) } & Mean \pm SD & $45.79 \pm 3.17$ & $52.60 \pm 9.44$ & \multirow{2}{*}{0.002} \\
\hline & Range & $43.1-57.9$ & $44-75.1$ & \\
\hline \multirow{2}{*}{ Pachy Apex $(\mu \mathrm{m})$} & Mean \pm SD & $516.00 \pm 48.17$ & $480.50 \pm 64.44$ & \multirow{2}{*}{0.056} \\
\hline & Range & $410-604$ & $372-586$ & \\
\hline \multirow{2}{*}{ Thinnest Location $(\mu \mathrm{m})$} & Mean \pm SD & $512.19 \pm 49.54$ & $458.93 \pm 69.75$ & \multirow{2}{*}{0.008} \\
\hline & Range & $405-602$ & $333-582$ & \\
\hline \multirow{2}{*}{$\mathrm{Kmax}$ (D) } & Median (IQR) & $45.7(44.2-47.0)$ & $52.1(48-60.5)$ & \multirow{2}{*}{$<0.001$} \\
\hline & Range & $43.1-60.5$ & $45.4-91.6$ & \\
\hline \multicolumn{5}{|l|}{ Left: } \\
\hline \multirow{2}{*}{ Astigmatism (D) } & Median (IQR) & $2.5(1.75-2.75)$ & $3.5(2.25-4.0)$ & \multirow{2}{*}{0.020} \\
\hline & Range & $1.5-3$ & $3.25-8$ & \\
\hline \multirow{2}{*}{ K1 (D) } & Mean \pm SD & $42.92 \pm 2.40$ & $45.86 \pm 3.51$ & \multirow{2}{*}{0.003} \\
\hline & Range & $38.7-50$ & $39-51$ & \\
\hline \multirow{2}{*}{ K2 (D) } & Mean \pm SD & $45.09 \pm 2.50$ & $50.66 \pm 4.11$ & \multirow{2}{*}{$<0.001$} \\
\hline & \begin{tabular}{|l|} 
Range \\
\end{tabular} & $40.2-52$ & $44.4-58.5$ & \\
\hline \multirow{2}{*}{ Pachy Apex $(\mu \mathrm{m})$} & Mean \pm SD & $520.00 \pm 46.61$ & $484.79 \pm 47.77$ & \multirow{2}{*}{0.030} \\
\hline & \begin{tabular}{|l|} 
Range \\
\end{tabular} & $415-596$ & $407-587$ & \\
\hline \multirow{2}{*}{ Thinnest Location $(\mu \mathrm{m})$} & Mean \pm SD & $516.23 \pm 46.38$ & $459.93 \pm 72.74$ & \multirow{2}{*}{0.005} \\
\hline & Range & $412-593$ & $310-581$ & \\
\hline \multirow{2}{*}{$\mathrm{Kmax}$ (D) } & Median (IQR) & $45.3(44.1-46.9)$ & $53.6(48.7-63.0)$ & \multirow{2}{*}{$<0.001$} \\
\hline & Range & $43.1-54.7$ & $45.5-66.7$ & \\
\hline
\end{tabular}

Mann-Whitney test, Independent t-test

A comparison between positive and negative keratoconus in right eyes of both groups was done and there was statistically significant difference. A Comparison between positive and negative keratoconus in left eyes of both groups was done and there was statistically significant difference (Table 5). 
Table (5): Comparison between -ve and +ve keratoconus in right and left eyes of both groups

\begin{tabular}{|c|c|c|c|c|c|c|}
\hline \multirow{2}{*}{\multicolumn{2}{|c|}{ Parameters }} & \multicolumn{2}{|c|}{ Group A } & \multicolumn{2}{|c|}{ Group B } & \multirow{2}{*}{ P-value } \\
\hline & & No. & $\%$ & No. & $\%$ & \\
\hline \multicolumn{7}{|l|}{ Right: } \\
\hline \multirow{6}{*}{ Result } & Normal & 20 & $76.9 \%$ & 5 & $35.7 \%$ & \multirow{6}{*}{0.024} \\
\hline & $\mathrm{KC1}$ & 2 & $7.7 \%$ & 1 & $7.1 \%$ & \\
\hline & $\mathrm{KC} 2$ & 1 & $3.8 \%$ & 3 & $21.4 \%$ & \\
\hline & KC3 & 1 & $3.8 \%$ & 3 & $21.4 \%$ & \\
\hline & KC4 & 0 & $0.0 \%$ & 2 & $14.3 \%$ & \\
\hline & Suspicious & 2 & $7.7 \%$ & 0 & $0.0 \%$ & \\
\hline \multirow{2}{*}{$\mathrm{KC}$} & Negative & 20 & $76.9 \%$ & 5 & $35.7 \%$ & \multirow{2}{*}{0.010} \\
\hline & Positive & 6 & $23.1 \%$ & 9 & $64.3 \%$ & \\
\hline \multicolumn{7}{|l|}{ Left: } \\
\hline \multirow{6}{*}{ Result } & Normal & 20 & $76.9 \%$ & 7 & $50.0 \%$ & \multirow{6}{*}{0.008} \\
\hline & $\mathrm{KC} 1$ & 0 & $0.0 \%$ & 0 & $0.0 \%$ & \\
\hline & $\mathrm{KC} 2$ & 2 & $7.7 \%$ & 3 & $21.4 \%$ & \\
\hline & KC3 & 0 & $0.0 \%$ & 4 & $28.6 \%$ & \\
\hline & $\mathrm{KC} 4$ & 0 & $0.0 \%$ & 0 & $0.0 \%$ & \\
\hline & Suspicious & 4 & $15.4 \%$ & 0 & $0.0 \%$ & \\
\hline \multirow{2}{*}{$\mathrm{KC}$} & Negative & 20 & $76.9 \%$ & 7 & $50.0 \%$ & \multirow{2}{*}{0.083} \\
\hline & Positive & 6 & $23.1 \%$ & 7 & $50.0 \%$ & \\
\hline
\end{tabular}

\section{DISCUSSION}

Keratoconus is the most common primary non inflammatory ectatic disease of the cornea. It is one of the major indications for corneal transplant in the developed countries (Sugar and Macsai, 2012).

Since keratoconus is typically characterized by the progression of irregular astigmatism, thinner cornea, and increased steepening of corneal curvature. Keratoconus is often first detected in the course of an eye examination and patients may be unaware of it, even though they complain of poor vision and have sought ocular care. Knowing the query prevalence of subclinical and clinical $\mathrm{KC}$ introduces much earlier interventions to hold the progression of the disease and guard against one of the most common cause of blindness.
There is an increase in the number of cases occurring nowadays in the world which may be due to technology advancement or better methods of diagnosis like corneal tomography and topography which dramatically improved the sensitivity of the diagnosis and detection of these ectatic disorders. This study was carried out to evaluate the prevalence of $\mathrm{KC}$ in astigmatic patients attending Al-Sayed Galal University Hospital. Retrospective analysis of the data presented on pentacam (Oculus) was done.

In the current study, the prevalence of $\mathrm{KC}$ among the selected cases of astigmatic patient's $\geq 1.5 \mathrm{D}$ is $(35 \%)$. This is a different finding from the prevalence of KC reported by Shakir and Alwan (2019) where $21 \%$ of the patients with astigmatism $\geq 2 \mathrm{D}$ attending the outpatient clinic. In our Study Group (A), the 
prevalence of $\mathrm{KC}$ was $23 \%$, nearly the same results as their study, but in Group (B), the prevalence of $\mathrm{KC}$ was $57 \%$. So, the total prevalence of $\mathrm{KC}$ in our study was higher than the one performed by them. On the other hand, they found that the higher prevalence rates for keratoconus were found as cylindrical power increased, which is agreed with our study.

Concerning the Prevalence of $\mathrm{KC}$ regarding as gender distribution in this study, there was a slight gender predilection, $57.1 \%$ were males and 42.9\% were females. Shakir and Alwan (2019) found that the female was predominant in which the prevalence rate was $61.1 \%$ and $38.9 \%$ for females and males respectively. This difference in results may be due to high male percentage in our study which include $55 \%$ vs $45 \%$ of females. They showed that the distribution as $54 \%$ females vs $46 \%$ males. In our study, there is no significant difference in keratoconus distribution between the two genders.

As regarding to the corneal parameters (mean anterior keratometer, pachymeter and the thinnest corneal thickness), Safarzadeh et al. (2016) reported similar results.

In our study, we have 6 cases that were diagnosed as unilateral keratoconus with suspicion in the other eye, Gordon-Shaag et al. (2015) found that more than one third of subjects with unilateral $\mathrm{KC}$ developed manifest $\mathrm{KC}$ in the other eye over 8 years. So, early diagnosis of subclinical and clinical keratoconic patients in grade 1and grade 2 is a very important point to all keratoconic patients, especially to astigmatic patient seeking for refractive correction procedures.

According to corneal topography, these astigmatic patients were diagnosed either non keratoconic or keratoconic. In cases that they are non keratoconic, different refractive procedures (Photorefractive keratectomy (PRK), LASIK and femtolasik) can be done safely. Therefore, patients diagnosed as keratoconus, should be warned from undergoing any of the refractive procedures.

Crosslinking (CXL) is the first surgical intervention, one of the earliest management steps to consider, especially in young patients. There should be no upper or lower age limit for CLX in KC eyes that show evidence of progression. CXL can delay keratoconus progression and decrease the demand for penetrating keratoplasty. Intracorneal ring segments (ICRS) induce an "arc-shortening effect" on the corneal lamellae and flatten the corneal center, as well as shift the corneal apex to a more central position that improves best-corrected visual acuity (BCVA) (Coskunseven et al., 2011).

The study by Ibrahim et al. (2016) reported that ICRS insertion assisted by femtosecond laser and corneal CXL provided improvement in visual acuity and keratometry results, which seems to suggest that it may be an effective treatment for the correction of early grades of keratoconus.

Penetrating keratoplasty (PKP) has been considered as the gold standard for the treatment of advanced keratoconus (Gordon-Shaag et al., 2015). 


\section{CONCLUSION}

Subjects with $1.5 \mathrm{D}$ or more of astigmatism who present to outpatient clinics should undergo corneal topography screening for early diagnosis of $\mathrm{KC}$ even if visual acuity is not affected.

\section{REFERENCES}

1. Coskunseven E, Kymionis GD, Tsiklis NS, Atun S, Arslan E and Jankov MR. (2011): One-year results of intrastromal corneal ring segment implantation (KeraRing) using femtosecond laser in patients with keratoconus. Am J Ophthalmol., 145: 775-779.

2. De Sanctis U, Loiacono C, Richiardi L, Turco D, Mutani B and Grignolo FM. (2011): Sensitivity and specificity of posterior corneal elevation measured by Pentacam in discriminating keratoconus/subclinical keratoconus. Ophthalmology, 115:1534-1539.

3. Fares U, Otri AM, Al-Aqaba MA and Dua HS. (2012): Correlation of central and peripheral corneal thickness in healthy corneas. Cont Lens Anterior Eye, 35:39-45.

4. Gordon-Shaag A, Millodot A, Shneor E and Liu Y (2015): The Genetic and Environmental Factors for Keratoconus. Bio Med Research International, 19: 738-748.

5. Hashemi H, Heydarian $S$ and Yekta $A$. (2018): High prevalence and familial aggregation of keratoconus in an Iranian rural population: a population-based study. Ophthalmic and Physiological Optics, 38:447455.
6. Ibrahim O, Elmassry A, Said A, Abdalla M, El Hennawi $H$ and Osman I. (2016): Combined femtosecond laser-assisted intracorneal ring segment implantation and corneal collagen cross-linking for correction of keratoconus. Clinical Ophthalmology (Auckland, NZ), 10:521-528.

7. Piñero DP, Alió JL, Alesón A, Vergara ME and Miranda M. (2010): Corneal volume, pachymetry, and correlation of anterior and posterior corneal shape in subclinical and different stages of clinical keratoconus. J Cataract Refractive Surg., 36:814-825.

8. Piñero DP, Juan CN and Alberto LM (2012): Characterization of corneal structure in keratoconus." Journal of Cataract\& Refractive Surgery, 38(12): 2167-2183.

9. Safarzadeh M, Nasiri N, Doostdar A and Kamali M. (2016): Anterior segment characteristics in normal and keratoconus eyes evaluated with a combined Scheimpflug/Placido corneal imaging device. Journal of Current Ophthalmology, 28: 106111.

10. Shakir AN and Alwan EH. (2019): Prevalence of Keratoconus in Patients with Astigmatism more than Two Diopters: A Cross-Sectional Study. International Journal of Medical Investigation, 8(2):12-22.

11. Sugar J and Macsai MS. (2012): What cause keratoconus? Cornea, 31:716-726.

12. Toprak I, Yaylalı V and Yildirim C. (2015): A combination of topographic and pachymetric parameters in keratoconus diagnosis. Contact Lens Anterior Eye, 38:357-362. 


\section{در اسة معدل إنتشار القرنية المخروطية بين مرضى اللانقطية المصرين}

محمد السيد فوزى عبدالحافظ، أحمد صلاح عبدالرحيم، نورالدين عبدالحميد عبدالحليم قسم طب وجراحة العيون، كلية الطب، جامعة الأزهر

Corresponding Author: Mohammed El-Sayed Fawzy Abd El-Hafez,

E-mail: mohammed-fawzy20@ hotmail.com

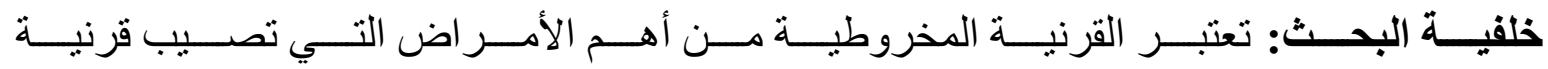

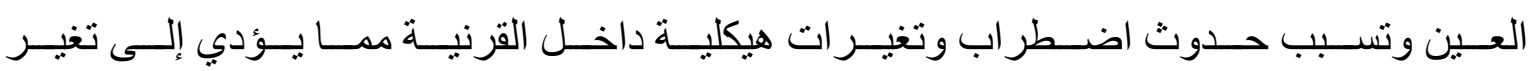

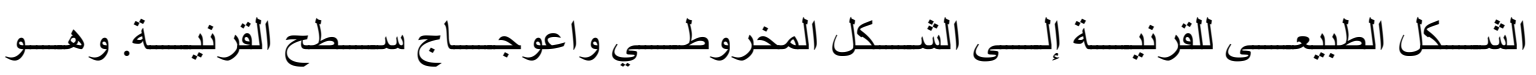

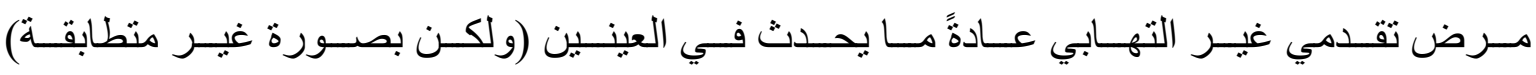

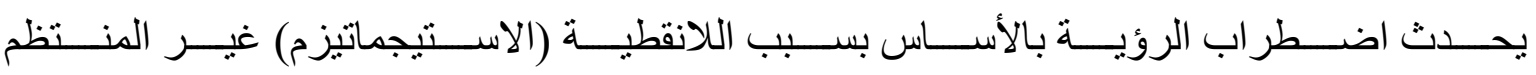

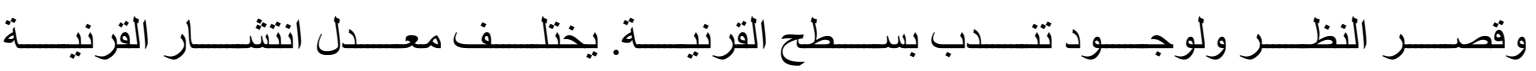

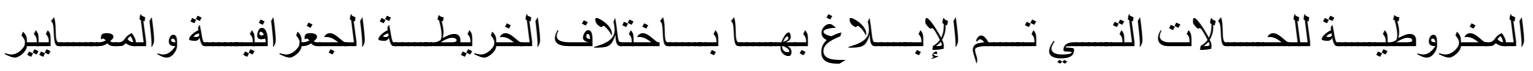
المتبعة في التشخيص ومجمو عة المرضى الذين نم اختيار هم.

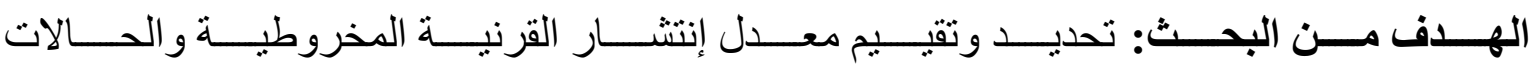

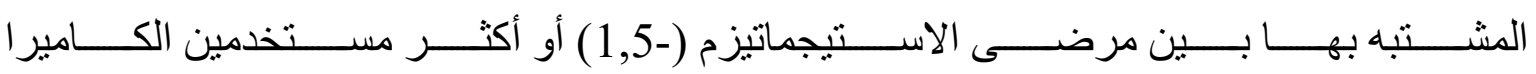
الخماسية (البنتاكام).

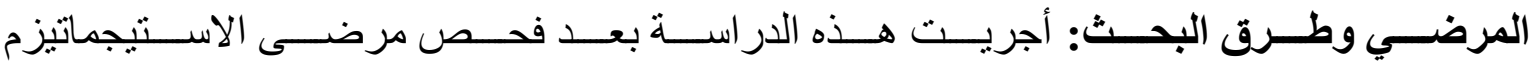

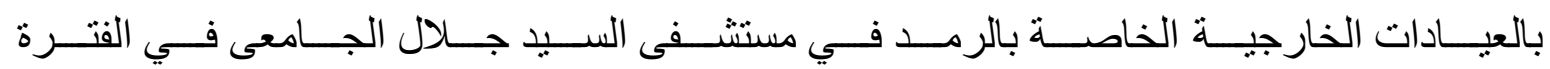

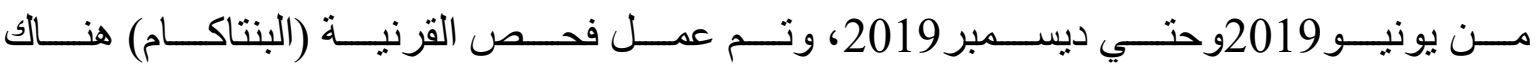

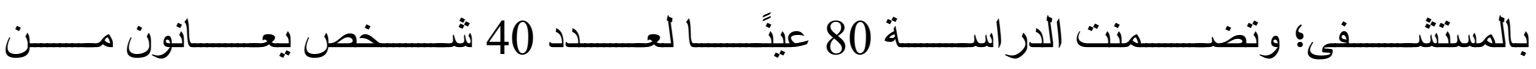

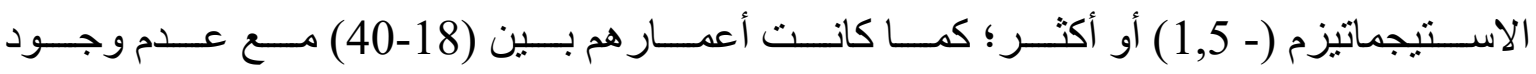
أي أمر اض أخرى بالعين.

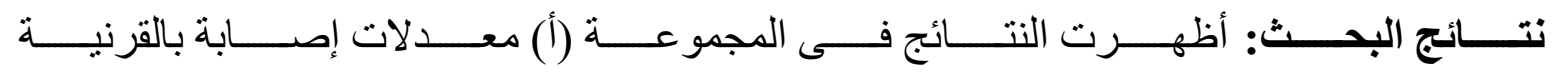

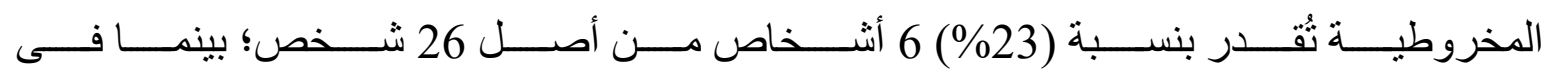

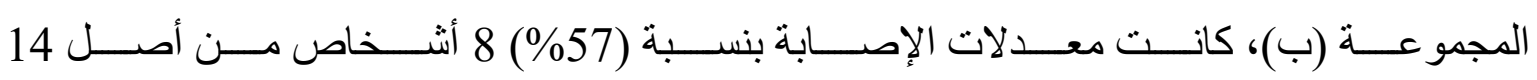




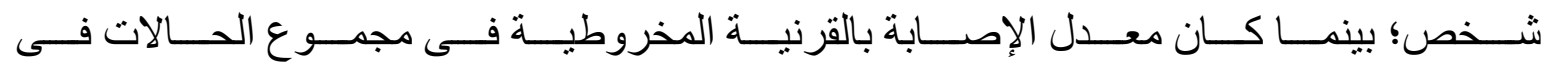

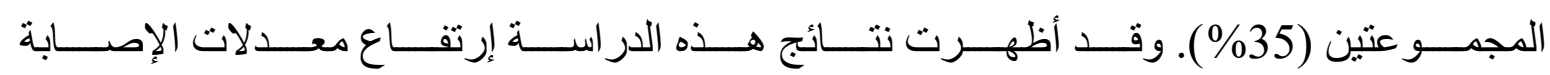

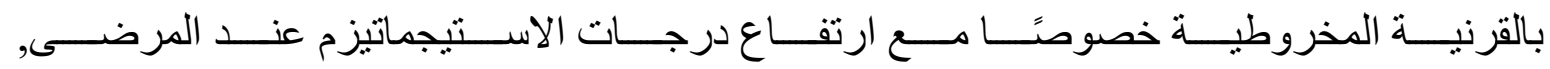

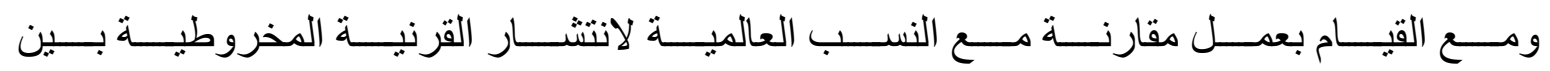

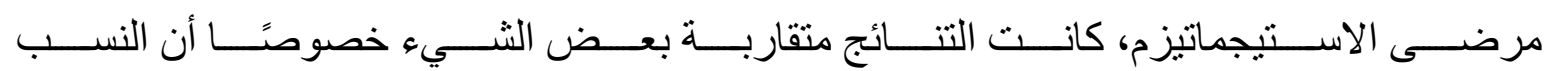

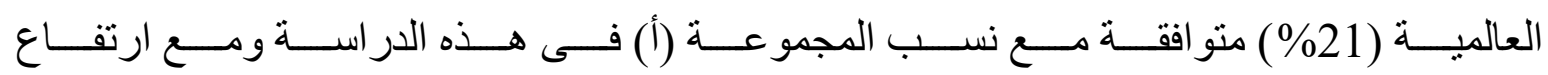

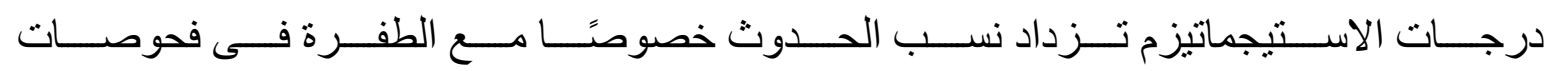
سطحي القرنية (الأمامي والخلفي) بإستخدام البنتاكام.

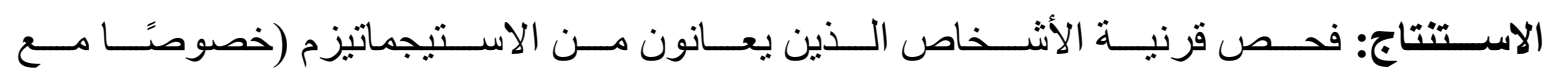

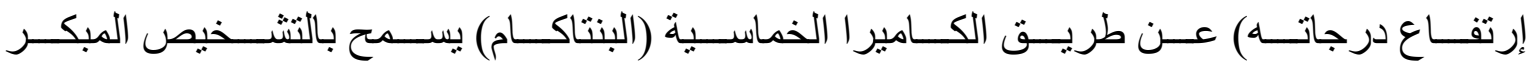

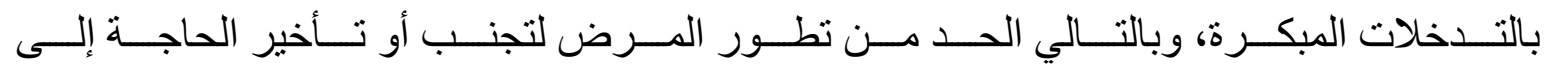
ترقيع القرنية.

الكلمات الدالة: القرنية المخروطية، اللابؤرية، بنتاكام. 